\title{
Modelagem Matemática: um olhar semiótico
}

\author{
Mathematical Modeling: a semiotic look
}

\author{
Michele Regiane Dias Veronez \\ Carina Chulek
}

\begin{abstract}
Resumo: O desenvolvimento de uma atividade de modelagem matemática a partir dos interpretantes produzidos por alunos de um primeiro ano do Ensino Médio é focalizado nesse texto à luz da teoria semiótica peirceana. A metodologia que subsidia o estudo realizado é de cunho qualitativo, já que temos por interesse discutir acerca dos signos produzidos pelos alunos ao longo do desenvolvimento de uma atividade de modelagem matemática. Como resultados, ponderamos que o processo de geração de (signos) interpretantes depõe (des)conhecimentos dos alunos, seja sobre Matemática, seja sobre a situação e/ou problema que desencadeou a atividade de modelagem matemática em foco. Além disso, esse processo favorece uma dinamicidade na geração dos interpretantes, proporcionada devido ao uso do software GeoGebra e leva os alunos a assumirem atitudes autônomas ao longo do desenvolvimento da atividade de modelagem matemática.
\end{abstract}

Palavras-chave: Modelagem Matemática. Semiótica. Tecnologia. Interpretantes.

Abstract: The development of a mathematical modeling activity regarding interpretants, produced by 10th grade students in high school, is highlighted in this text using Peircean semiotic theory. The methodology supporting the study is of qualitative nature, since we are interested in discussing the signs produced by students throughout the development of a modeling activity. As for the results, we ponder that the process of generating interpretants (signs) reveals the students' not only mathematical lack of knowledge, but also a lack of knowledge about the situation and/or the problem that triggered the mathematical modeling activity in focus. Additionally, this process favors a dynamism in the generation of interpretants, due to the use of Geogebra software, and gets the students to take on autonomous attitudes along the development of the mathematical modeling activity.

Keywords: Mathematical Modeling. Semiotic. Technology. Interpreter.

\section{Introdução}

Vivemos em uma sociedade de constantes evoluções tecnológicas e que requer um olhar diferenciado para a educação. Já que alternativas pedagógicas que auxiliam nos processos de ensino e de aprendizagem de nossos alunos existem e podem favorecer uma formação diferenciada para eles, independentemente do nível de

Michele Regiane Dias Veronez Doutorado em Ensino de Ciências e Educação Matemática. Professora do Programa de Pós-Graduação em Educação Matemática da Universidade Estadual do Paraná (UNESPAR), campus União da Vitória. Paraná, Brasil. iD orcid.org/0000-0001-9464-1498 $\bowtie$ miredias@gmail.com

Carina Chulek Mestranda em Ensino de Ciências Naturais e Matemática pela Universidade Estadual do Centro-Oeste (UNICENTRO). Professora no Colégio São Bento. Paraná, Brasil. iD orcid.org/0000-0002-8286-3488 $\bowtie$ carina.chulek@gmail.com

Recebido em 29/02/2020 Aceito em 02/04/2020 Publicado em 22/04/2020 ensino que estão, optamos, neste estudo, dentre essas alternativas, focalizar a Modelagem 


\section{Matemática1.}

Na perspectiva da Educação Matemática, a Modelagem Matemática consiste em uma atividade de busca por solução para um determinado problema (ALMEIDA, SILVA e VERTUAN, 2013), que pode ser enunciado pelo professor, pelo aluno ou por um consenso entre ambos. Esse problema, geralmente, advém de uma situação externa ao contexto matemático levada em conta para ser estudada e analisada a partir de lentes da Matemática e compreendida em todos os seus aspectos, conforme o recorte e hipóteses consideradas.

A busca por tal solução, entretanto, envolve, para além de conhecimentos associados à situação que o subsidia, um conjunto de procedimentos e encaminhamentos constituídos por conceitos e conhecimentos matemáticos e requer, dos alunos, uma participação ativa, inclusive, quando da análise crítica da solução obtida e; do professor, uma atitude de orientar e guiar os alunos ao longo de suas escolhas e em relação aos seus (des)conhecimentos. Nesse sentido, professor e alunos precisam trabalhar em parceria.

É também na busca por solução para o problema que acontece a produção de uma variedade de signos, que são por nós olhados, a partir de lentes da Semiótica, segundo as orientações de Peirce (2005), que argumenta que o signo é alguma coisa que expressa, comunica ou representa algo; sem que haja substituição daquilo que o signo se refere. Particularmente, neste estudo, consideramos o potencial da Modelagem Matemática na produção de signos, no contexto em que a tecnologia se faz presente.

Ao considerar tal cenário, elegemos a seguinte questão de investigação: Que signos são produzidos em atividades de modelagem matemática quando os alunos recorrem também ao uso de tecnologia, visando desenvolvê-las?, tendo como objetivo analisar a produção desses (signos) interpretantes ao longo de uma atividade de modelagem matemática desenvolvida por alunos de uma primeira série de Ensino Médio, de uma escola privada, no estado do Paraná.

O fato de trazer à tona uma interlocução entre Semiótica e Modelagem Matemática aliada ao uso de tecnologia é por nós entendido como uma possibilidade de evidenciar aspectos teóricos da Modelagem Matemática e da Semiótica em uma prática realizada em uma turma da Educação Básica. Tal atitude também viabiliza com que as ações dos alunos ao longo da atividade de modelagem matemática trazida para discussão sejam refletidas a partir dos signos que eles

\footnotetext{
10 termo "Modelagem Matemática" (em maiúsculo) é utilizado quando se faz referência à abordagem metodológica
} e o uso dessa expressão em minúsculo está associado à atividade decorrente dessa abordagem. 
produzem enquanto intentam solucionar o problema que originou tal atividade.

\title{
2 Modelagem Matemática e Semiótica: nossos aportes teóricos
}

A Modelagem Matemática tem ganhado espaço na sala de aula em todos os níveis de ensino seja para introduzir um novo conteúdo, para exemplificar aplicações de conceitos, para promover o desenvolvimento da criatividade dos alunos, para analisar situações que sejam do interesse deles. Dada essa complexidade de possibilidades de trabalho com Modelagem Matemática, aliada às diferentes formas de compreendê-la, nos apoiamos para o desenvolvimento deste estudo que uma atividade de modelagem matemática

\begin{abstract}
pode ser descrita em termos de uma situação inicial (problemática), de uma situação final desejada (que representa uma solução para a situação inicial) e de um conjunto de procedimentos e conceitos necessários para passar da situação inicial para a final. Nesse sentido, realidade (origem da situação inicial) e Matemática (área em que os conceitos e os procedimentos estão fundamentados) são domínios diferentes que passam a se integrar, e, em diferentes momentos, conhecimentos matemáticos e não matemáticos são acionados e/ou produzidos e integrados (ALMEIDA, 2010, p. 399).
\end{abstract}

É na transição da situação inicial para a final que "relações entre Matemática e realidade podem aparecer" (VERTUAN, 2007, p. 34) e que conceitos podem ser construídos, ao mesmo tempo em que se definem os recursos tecnológicos a serem utilizados. Segundo Borssoi, Silva e Almeida (2013, p. 1), "a Modelagem Matemática como alternativa pedagógica pode se valer desses recursos como uma oportunidade de promover experiências de aprendizagem em que os alunos possam aprender fazendo". Assim sendo, "a Matemática requerida nas aulas com modelagem e computador pode ser diferente daquela usada na ausência desses elementos" (ALMEIDA, SILVA e VERTUAN, 2013, p. 30).

O fato de uma atividade de modelagem matemática emergir de uma situação inicial, geralmente relacionada com aspectos da realidade que circunda o contexto dos alunos, pode favorecer com que se tenha possibilidades de abordar situações que vêm atreladas a imagens e, consequentemente, sugerir com que sejam analisadas a partir do uso de recursos tecnológicos, como o software GeoGebra. Esse software pode ser utilizado como um recurso que subsidia as ações, opções e conclusões dos alunos e levá-los a recorrer a procedimentos e encaminhamentos que conduzem à uma solução para o problema estudado.

O uso de tecnologias em associação com atividades de modelagem matemática, 
independente de qual seja - planilhas, sistemas de álgebra de computador ou software de geometria dinâmica - sempre pode contribuir nas tarefas de visualizar modelos, simular processos reais ou ser usados para controlar resultados matemáticos (SILLER e GREEFRATH, 2010).

De acordo com Greefrath (2011), as tecnologias, como recurso disponível para os alunos nas atividades de modelagem matemática, favorecem o desenvolvimento de ações que antes eram exclusivamente humanas e podem auxiliar no processo de resolução e de obtenção de uma solução para o problema em estudo em tempo menor que quando da ausência delas. Também, mobilizam alunos e professor no sentido de requerer deles atitudes diferentes daquelas exigidas em aulas nas quais recursos tecnológicos não estão presentes.

Ademais, recursos como o software GeoGebra, que é dinâmico, pode contribuir na compreensão e na análise dos alunos acerca de situações alicerçadas em imagens, de diferentes naturezas. Esse software, além de sua característica dinâmica, tem uma variedade de recursos que permitem ações que no papel e no lápis poderiam ser bastante limitadas e, devido a isso, 0 modo de ver e analisar determinada situação também pode ganhar uma conotação diferente. Para Hertleif (2017) a dinâmica de alguns softwares é especialmente útil para uma adaptação flexível de modelos já construídos, com o objetivo de simular possíveis soluções ou melhorar o modelo utilizado.

O uso do GeoGebra no desenvolvimento de atividades de modelagem matemática também pode levar os alunos a compreender e mobilizar objetos matemáticos a partir de signos de diversas naturezas, por eles produzidos, e possibilitar com que eles estabeleçam relações entre tais signos. Como esses signos se referem a algum aspecto inerente ao desenvolvimento da atividade de modelagem matemática, Almeida, Silva e Veronez $(2015$, p. 2) afirmam que "estes signos são, por um lado, meios para pensar sobre objetos e relações matemáticas e, por outro, produto de tais pensamentos".

A referência aos signos que ora fazemos seguem os pressupostos da teoria semiótica peirceana, que se assenta na seguinte definição de signo, evocada por Peirce (2005):

Um signo ou representamen, é aquilo que, sob certo aspecto ou modo, representa algo para alguém. Dirige-se a alguém, isto é, cria, na mente dessa pessoa, um signo equivalente, ou talvez um signo mais desenvolvido. Ao signo assim criado denomino interpretante do primeiro signo. O signo representa alguma coisa, seu objeto. Representa esse objeto não em todos os seus aspectos, mas com referência a um tipo de ideia que eu, por vezes, denominei fundamento do representamen (p. 46). 
Nesse sentido, Peirce (2005) denota que signo representa alguma coisa para alguém; 0 signo pode ser qualquer coisa, e ainda, essa coisa pode estar inserida em qualquer lugar, sendo no universo físico ou no pensamento. Afirma ainda que o signo está em constante transformação, que está associada à capacidade do intérprete de gerar signos em sua mente ao passo que se envolve com determinadas tarefas.

Quando Peirce (2005), em sua teoria, refere-se ao signo como uma representação de alguma coisa, ele refere-se ao objeto, primeiro elemento da sua tríade, "o signo somente pode representar um objeto de certa forma e numa certa capacidade" (BORSSOI, SILVA e ALMEIDA, 2013 , p. 4). Assim, signo e objeto são coisas distintas, porém, para representar o objeto do signo é preciso um novo elemento, que neste caso é chamado interpretante; "ao signo, assim criado, denomino interpretante do primeiro signo" (PEIRCE, 2005, p. 46). É nesse sentido que o autor defende que o "objeto de um Signo, ou seja, que ele pressupõe uma familiaridade com algo a fim de veicular alguma informação anterior sobre esse algo" (PEIRCE, 2005, p. 56-57), é de algum modo expresso por outro signo denominado interpretante. Desta forma, o interpretante é gerado da relação entre o signo e o seu objeto.

Ferreira (2006, p. 58) afirma que "o interpretante2 , substitui o objeto real na mente do intérprete de certo modo, num certo contexto". Desta forma, o interpretante substitui o objeto real da mente do intérprete, ou seja, "o objeto real' é inatingível pela percepção" (SILVA, 2008, p. 37), então a interpretação que o intérprete faz de um signo é um processo dinâmico. Neste contexto, Santaella (2009) argumenta que

\begin{abstract}
a partir da relação de representação que o signo mantém com seu objeto, produz-se na mente interpretadora um outro signo que traduz o significado do primeiro (é o interpretante do primeiro). Portanto, o significado de um signo é outro signo - seja este uma imagem mental ou palpável, uma ação ou mera reação gestual, uma palavra ou mero sentimento de alegria, raiva [...] uma ideia, ou seja, lá o que for - porque esse seja lá o que for, que é criado na mente pelo signo, é um outro signo (tradução do primeiro) (p. 58-59).
\end{abstract}

Sendo assim, o interpretante também é um signo que gera um novo interpretante; novo signo. Peirce (2005) afirma que

o signo cria algo na mente do Intérprete, algo esse que foi também, de maneira relativa e mediada, criado pelo Objeto do Signo, embora o Objeto seja essencialmente diverso

\footnotetext{
20 interpretante, na verdade, é uma dinâmica sígnica que se cria na mente do intérprete. É o próprio resultado
} significante, ou seja, o efeito do signo. É, em suma, um outro signo, já que as ideias são signos. 
do Signo. Ora, esta criatura do Signo chama-se Interpretante. Ele é criado a partir do signo e é também signo (p. 74).

Cada geração de interpretante, signos, depende do que acontece na mente do intérprete. $E$, ainda de acordo com a ótica peirciana, a geração de interpretantes, consequentemente de signos, é uma ação da mente do intérprete. Segundo Nöth (2008), essa ação faz com que o signo tenha um efeito cognitivo sobre o intérprete e gere novos signos. É relevante pensar que interpretantes podem manifestar atos interpretativos particulares que estão associados às particularidades e experiências de cada intérprete, produzindo, a partir de suas especificidades, signos de naturezas diversas.

Esse pensamento, portanto, está fundamentado nas indicações de Peirce (2005) de que 0 interpretante decorre do efeito do signo no intérprete. Neste contexto, o autor divide os interpretantes em três classes: interpretante imediato, interpretante dinâmico, e interpretante final. O primeiro é o que o signo causa ou produz ao interpretante, o segundo é o efeito que esse signo faz ao interpretante e o terceiro, como Peirce $(2005$, p. 164) relata, "é aquilo que finalmente se decidiria ser a interpretação verdadeira se se considerasse 0 assunto de um modo tão profundo que se pudesse chegar a uma opinião definitiva".

Para chegar ao interpretante final é necessário que o processo de interpretação aconteça, processo este que acontece na semiose. Em relação a esse processo Peirce (2005, p. 74) assevera que "qualquer coisa que conduz alguma outra coisa (seu interpretante) a referir-se a um objeto ao qual ela mesma se refere (seu objeto) de modo idêntico, transformando-se 0 interpretante, por sua vez, em signo, e assim sucessivamente ad infinitum". Este processo de geração de interpretantes considera a relação triádica do signo, objeto e interpretante, pois o signo gera interpretante, que se torna novo signo, que constitui nova tríade.

Em Modelagem Matemática esse processo de geração de interpretantes também segue princípios da semiose, ou seja, no desenvolvimento de uma atividade de modelagem matemática "os signos se configuram como meios pelos quais os alunos manifestam seus pensamentos e conhecimentos enquanto buscam encontrar uma solução para o problema advindo da situação em foco" (VERONEZ e ALMEIDA, 2017, p. 144). Ademais, as autoras afirmam que os signos produzidos pelos alunos ao longo de atividades de modelagem matemática podem ser implícitos ou explícitos, podendo revelar ou sugerir intenções e conhecimentos dos alunos enquanto buscam por uma solução para o problema investigado. 
Borssoi, Silva e Almeida (2013), ao discutir sobre os signos em contexto que consideram recursos tecnológicos, afirmam que os intérpretes (alunos) os produzem com maior dinamicidade em diversos momentos da atividade de modelagem matemática, ou seja, "quando problematizam, experimentam, planejam, constroem modelos, e visualizam resultados" (p. 14).

Na seção que segue abordamos os aspectos metodológicos que subsidiam nosso estudo.

\section{Aspectos metodológicos}

A atividade de modelagem matemática que trazemos foi desenvolvida no contexto de uma investigação maior ${ }^{3} \mathrm{e}$, nesse sentido, os alunos já tinham alguma familiaridade com Modelagem Matemática. Ao longo do desenvolvimento dessa atividade o professor buscou, seguindo orientações de Almeida e Dias (2004), no que refere ao terceiro momento 4 de familiarização dos alunos com Modelagem Matemática, assumir um papel de orientador, deixando e incentivando os alunos a atuar de forma crítica e reflexiva em relação às suas escolhas. Em suas orientações, as autoras argumentam que as atividades de modelagem matemática sendo implementadas de maneira gradativa podem favorecer com que o aluno confie mais em si, além disso, passar por esses três momentos de familiarização, pode contribuir para que sua compreensão de como acontece o processo de Modelagem Matemática, a resolução de problemas e de como analisar as resoluções e soluções encontradas aumentem (ALMEIDA e DIAS, 2004). De acordo com Almeida e Silva (2014, p. 10) a familiarização "trata-se de um encaminhamento para colocar 0 aluno em contato com a prática de fazer modelagem de forma gradativa".

Para a coleta e o tratamento dos dados que subsidiam o estudo realizado nos pautamos nas assertivas de Denzin e Lincoln (2006), que esclarecem que a abordagem qualitativa exige uma postura interpretativa e naturalista do mundo, do qual o observador está inserido. Outra característica da pesquisa qualitativa é que ela tem como fonte de coleta de dados o espaço natural no qual o pesquisador está inserido, ou seja, o pesquisador está em contato direto com o ambiente investigado. Desse modo, o pesquisador se torna responsável pelos dados coletados, pela leitura deles e, também, por sua interpretação e análise (GOLDENBERG, 1999).

\footnotetext{
${ }^{3}$ Essa atividade compõe um conjunto de atividades de modelagem matemática desenvolvidas, conforme orientações de Almeida e Dias (2004), no contexto de uma investigação de mestrado da segunda autora.

4 No terceiro momento de familiarização dos alunos com Modelagem Matemática, Almeida e Dias (2004, p. 7) sugerem que os alunos, distribuídos em grupos, conduzam um "processo de Modelagem, a partir de um problema escolhido por eles, devidamente assessorados pelo professor".
} 
A atividade de modelagem matemática sob a qual nos debruçamos foi desenvolvida por um dos grupos de alunos ${ }^{5}$ de uma primeira série do Ensino Médio de uma escola privada do estado do Paraná, o qual escolheu um lago da cidade como tema para estudo. Para discorrermos a respeito do desenvolvimento dessa atividade de modelagem matemática consideramos as gravações em áudio das aulas nas quais os alunos a desenvolveram e os registros por eles produzidos. Quando da necessidade de evidenciar o professor ou os alunos ao passo que discorremos sobre tal atividade, o fazemos nos referindo ao professor por Prof. e aos alunos por $A 1, A 2$ e $A 3$, já que esse grupo era composto por três alunos.

\section{Uma atividade de modelagem matemática: sua descrição}

O Lago da cidade de Pitanga, Paraná, foi o tema escolhido pelos alunos para a atividade de modelagem matemática por eles desenvolvida no terceiro momento de familiarização com Modelagem Matemática proposto por Almeida e Dias (2004). Esse tema surgiu do interesse dos alunos em pesquisar sobre o Lago, considerado ponto de lazer na cidade, no sentido de investigar sobre a instalação de pedalinhos ${ }^{6}$ nesse lago de modo a favorecer um atrativo a mais nesse local.

A busca por imagens do lago (Figura 1), bem como da medida de seu perímetro - que corresponde a 506,54 m - e do pedalinho por eles assumido como sendo adequado considerar (Figura 2) e de suas medidas - comprimento de 2,20 m e 1,50 m de largura -, levou-os a definir a seguinte questão para estudo: Quantos pedalinhos cabem no lago?

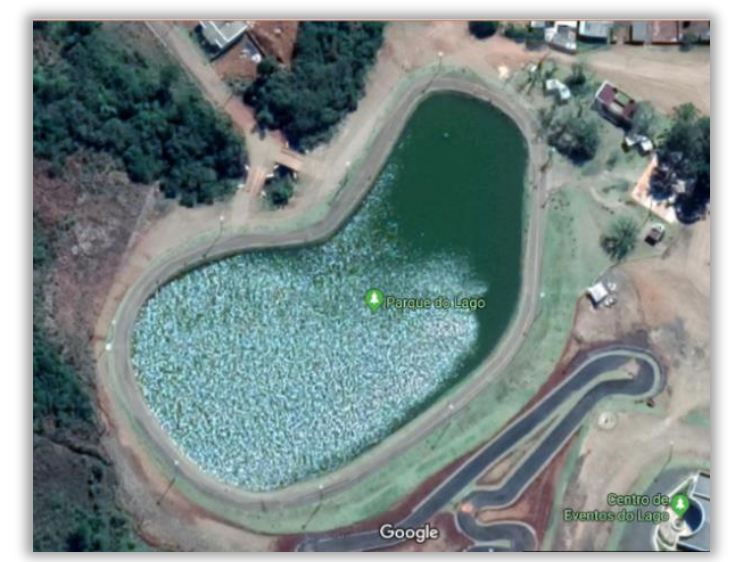

Figura 1: Lago do Parque Municipal — perímetro de 506,54 m (Google Maps7)

\footnotetext{
5 Os alunos da turma se organizaram em cinco grupos (G1, G2, G3, G4 e G5) e cada um deles foi constituído pelos próprios alunos.

${ }^{6}$ É uma espécie de embarcação que pode comportar uma ou mais pessoas, acionado por meio de pedais.

7 Disponível em: https://www.google.com.br/maps/@-24.7680571,-51.7684491,220m/data=!3m1!1e3
} 


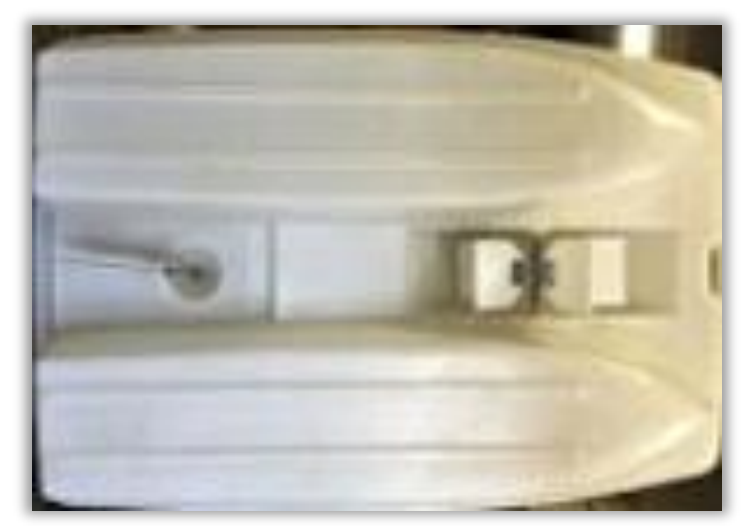

Figura 2: Visão inferior do pedalinho - comprimento: 2,20 m (Google Maps ${ }^{8}$ )

Considerado o problema em questão, os alunos exportam a imagem do lago no GeoGebra e recorrem às ferramentas do software para obter o perímetro e a área da imagem do lago e obtém que a área real do lago é 1546,45 $\mathrm{m}^{2}$, a partir de uma propriedade matemática que relaciona perímetro e área.

A necessidade de considerar que o pedalinho precisa de um espaço para girar — hipótese assumida pelos alunos -, leva os alunos, ao exportarem a imagem da base do pedalinho no GeoGebra, a considerar nela uma circunferência circunscrita (Figura 3) e, a partir disso, obter a área ocupada, no lago, por cada pedalinho. Depois de obtido o valor das áreas - área do lago e área ocupada por cada pedalinho —, os alunos obtêm que o lago suportaria um total de 2750 pedalinhos.

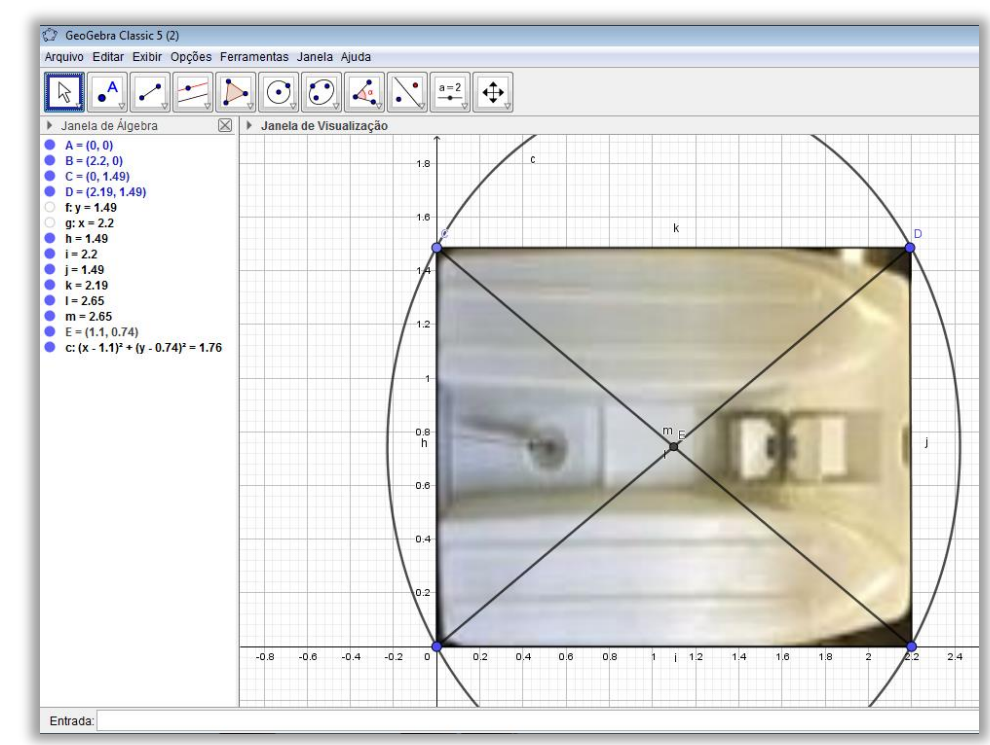

Figura 3: Traçado da circunferência circunscrita, realizado pelos alunos (Acervo da Pesquisa)

\footnotetext{
${ }^{8}$ Disponivel em: https://www.smartpier.com/images/fotos/Cisne/Miniaturas/PB-210-Pedalinho-Cisne-Fundo02_Pq.jpg
} 
Embora tenham resolvido o problema do ponto de vista matemático, os alunos concluem que não seria interessante ter essa quantidade de pedalinhos no lago. Contudo, aventam que a prefeitura poderia investir na aquisição de alguns para tornar o passeio no lago ainda mais atrativo para a população da cidade e visitantes.

\section{Nossa análise semiótica}

A proposição de desenvolver a atividade de modelagem matemática que tem o lago como tema foi de um dos três alunos que compõem o grupo G1. O Episódio 1 ilustra as primeiras ações empreendidas por eles com vistas a desenvolver tal atividade de modelagem.

\section{Episódio 1}

A1: Oi professora, a gente pensou em fazer alguma coisa sobre o lago.

Prof: É uma ótima ideia, mais o que, por exemplo?

A2: Pensamos em ver se dava para coloca pedalinhos lá no lago, vai que conseguimos provar que é uma boa ideia colocar pedalinho no lago.

A1: É professora, os pedalinhos como forma de lazer.

Prof: É uma boa ideia, mas como que vocês vão fazer isso?

A2: Simples, primeiro calculando a área do lago.

Prof: Então vocês terão que analisar esta situação em três etapas. Primeiro, calculando a área do lago; segundo, pesquisando sobre os pedalinhos; e, depois sobre os pedalinhos no lago.

A2: Sim prof, vamos agora pesquisar como podemos calcular a área do lago apenas. [...]

Prof: E como vocês vão pesquisar sobre ele?

A3: Ah, a gente já pesquisou no Google Maps prof, e tiramos um print do lago.

Neste diálogo, o interpretante imediato enunciado pelo aluno A2: calculando a área do lago, retrata uma primeira intenção que o aluno tem para resolver o problema. Mesmo não tendo um problema formulado, a partir desse interpretante é sinalizado que ele conhece algumas 
estratégias, levando em conta aspectos da coleta de informações, que podem auxiliar na elaboração de uma questão a investigar. Quando o aluno A3 fala que "já pesquisou no Google Maps e tiramos um print do lago" tem-se um interpretante imediato que revela uma primeira intenção deste aluno, que brevemente gera o interpretante dinâmico "tiramos um print do lago". Este interpretante, ilustrado na Figura 1, passa a se constituir ele próprio um objeto e provoca os alunos a pensarem em um problema a investigar.

Este interpretante, associado aos conceitos de área e à sua interpretação pelos intérpretes - alunos que desenvolvem a atividade —, os provoca a discutir acerca do problema a investigar e dos meios possíveis de resolvê-lo. O Episódio 2 ilustra esse fato.

\section{Episódio 2}

Prof: Com essa imagem dá para fazer um monte de coisa, mas, o que vocês pretendem?

A1: Sei lá prof, será que a gente pode calcular a área?

Prof: Mas como que vocês vão calcular a área?

A2: Como vamos ter que descobrir, ou você pode nos contar.

A3: Ela não vai contar para a gente.

Prof: Não mesmo, eu posso ajudar vocês, mas não contando.

A2: Se a gente calcula a área do lago, a gente pode ver quantos pedalinhos cabem no lago.

A1: Mas só ver quantos pedalinhos dá para por no lago.

A3: Tá aí nosso problema. [...]

A1: Professora a gente conseguiu algumas informações sobre o lago que a gente acha importante.

Prof: É? Que informações que vocês coletaram?

A1: Professora a gente foi na prefeitura, e explicamos que estamos fazendo uma atividade de matemática. Que a professora deixou a gente pesquisa sobre o que a gente quisesse, e que decidimos pesquisar sobre o lago. 
A3: É, daí perguntamos se ele podia passar algumas informações sobre o lago.

A1: Daí ele disse que podia passar o perímetro do lago, ajuda já né?

Prof: Ajuda sim.

A2: Então professora, nós viemos com o perímetro do lago, e com a imagem do Google Maps do lago, e agora?

Prof: Agora vocês precisam decidir o que vocês querem saber com esses dados.

A3: Queremos saber quantos pedalinhos cabem no lago sem se baterem.

Prof: Hummmm, é um bom problema.

A1: Como que a gente vai fazer isso?

Prof: Vocês que precisam me contar.

A2: Professora a gente pode colocar a imagem no GeoGebra né.

Prof: Claro que sim.

A2: Fica assim?

Quando A2 fala "calcula a área do lago, a gente pode ver quantos pedalinhos cabem no lago" enuncia um problema que seguidamente é aceito por todo o grupo. Tal enunciação corresponde a um interpretante imediato. Esse interpretante imediato associado à imagem da Figura 2 produz os interpretantes dinâmicos explicitados na indicação de calcular a área do lago e na sugestão de utilizar o GeoGebra para isto.

A enunciação de utilizar o GeoGebra embora ganhe conotação de interpretante final por parte dos alunos por reconhecerem que o problema estaria resolvido a partir dessa ação, passa a ser um novo interpretante imediato quando eles percebem que necessitam explorar mais sobre 0 software.

Com vistas a solucionar o problema, que agora aparece de fato formulado, e tendo a informação do perímetro e a imagem do lago (Figura 1), os alunos enunciam algumas hipóteses (Quadro 1). Essas hipóteses, no entanto, além de serem interpretantes imediatos porque revelam 
uma primeira impressão do intérprete, são também interpretantes dinâmicos, já que produzem um efeito no intérprete. Esses interpretantes, associado aos conceitos de área e à interpretação do signo pelo intérprete, provoca a produção do signo interpretante imediato - traçado da região poligonal do lago — representado na Figura 4.

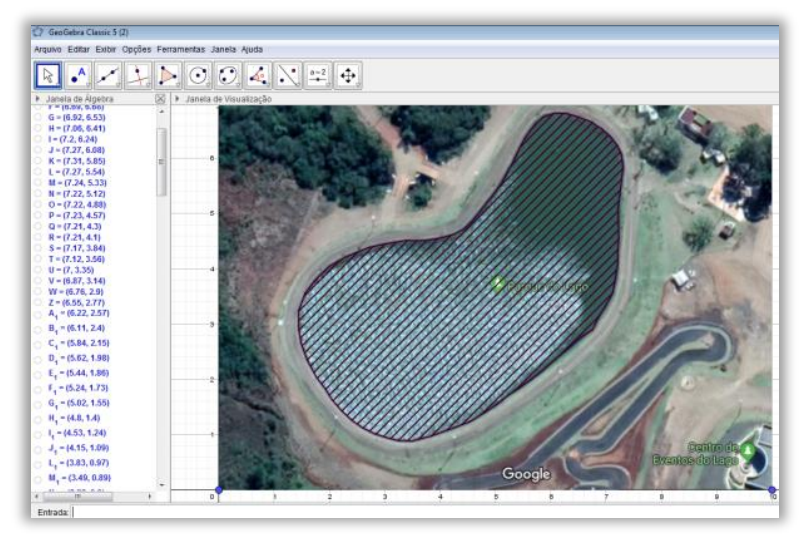

Figura 4: Região poligonal traçada com o auxílio do GeoGebra (Acervo da Pesquisa)

Quadro 1: Hipóteses

H1: O lago não possui formato de um polígono regular.

H2: É possível calcular a área do lago no GeoGebra utilizando apenas as ferramentas do software.

Fonte: Dados da Pesquisa

As hipóteses $\mathrm{H} 1$ e $\mathrm{H} 2$ e a região poligonal do lago são interpretantes que revelam intenções dos intérpretes e, embora se relacionem com as possibilidades de uma eventual resposta ao problema enunciado, sugerem que o traçado da região poligonal mesmo que indispensável, não é suficiente. 0 Episódio 3 retrata o diálogo entre os alunos em relação a esse aspecto.

\section{Episódio 3}

A1: Olha como ficou bonitinha, mas espera aí, não é um polígono regular, como que a gente vai calcular a área?

A3: Do mesmo jeito que fosse um polígono regular, pela ferramenta do GeoGebra né. [...]

Prof: Isso mesmo, assim vocês conseguem demarcar bem o polígono que vocês construíram. 
A1: Então professora até fica fácil assim né, se a gente conseguir utilizar as ferramentas do programa né.

Prof: É sim.

A2: Vamos calcular a área então. Com o GeoGebra dá para calcular o perímetro também né prof?

Prof: Dá sim.

A fala de A1 "mas espera aí, não é um polígono regular", é um interpretante dinâmico que sugere que o grupo elabore estratégias, utilizando ferramentas do software GeoGebra para obterem a área e o perímetro da região poligonal da superfície do lago. Isso ocorre porque os conhecimentos deles ainda são insuficientes para calcular tal área e perímetro. A Figura 5 ilustra que a estratégia dos alunos para obtenção da área e do perímetro do lago (Quadro 2) foi selecionar os itens, nas ferramentas do software, que possibilitam tais medidas.

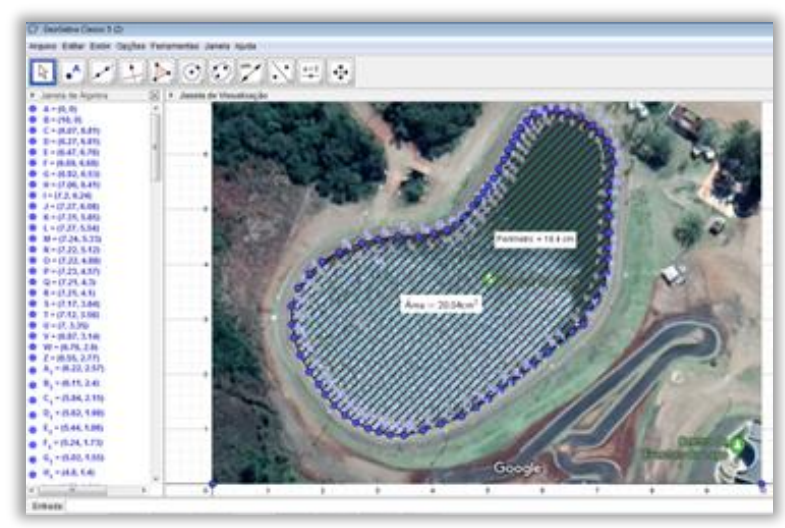

Figura 5: Ferramenta do Software GeoGebra para calcular a área (Acervo da Pesquisa)

Quadro 2: Informações coletadas no GeoGebra

Perímetro do Lago no GeoGebra: $18,4 \mathrm{~cm}$

Área do Lago no GeoGebra: $20,04 \mathrm{~cm}^{2}$

Fonte: Dados da Pesquisa

Os valores da área e do perímetro do lago por ora parecem caracterizar-se interpretantes finais, contudo, conforme Episódio 4, esses interpretantes passam a se constituir novos signos.

\section{Episódio 4}

A3: Então professora, nós temos o perímetro do Lago de verdade que 
os engenheiros da prefeitura passaram, temos a área do lago e o perímetro do lago aqui no GeoGebra. E agora? [...]

Prof: Voltem ao problema que vocês montaram o que vocês precisam fazer?

A2: O lago de verdade e o lago no GeoGebra são o mesmo, mas um é muito maior que o outro, não são semelhantes professora?

Prof: São sim.

A1: É mesmo, podemos usar razão e proporção.

O comentário "O lago de verdade e o lago no GeoGebra são o mesmo, mas um é muito maior que o outro, não são semelhantes professora?" do aluno A2 gera um novo ciclo de interpretantes. Esse comentário é um interpretante com características, ora de interpretante imediato, ora de interpretante dinâmico. Configura-se um interpretante imediato porque essa afirmação traz uma primeira impressão de A2 e corresponde a um interpretante dinâmico porque revela o efeito que o interpretante imediato faz ao intérprete. A fala de A1 "podemos usar por razão e proporção" denota tal efeito. As medidas do perímetro e da área do lago coletados do GeoGebra passam a se construir um objeto e associados aos conceitos de razão e proporção levam os alunos a discutirem as próximas estratégias a serem tomadas. 0 Episódio 5 expõe esse fato.

\section{Episódio 5}

A2: Professora, a razão encontrada quando divide o valor de dois lados proporcionais em dois polígonos semelhantes e do perímetro é a mesma.

A1: Eu acho que a gente já tem as informações que a gente precisa. [...] A1: Mas professora que acho que a gente precisa colocar tudo na mesma unidade de medida.

A3: É mesmo, tem que deixar tudo em $\mathrm{cm}$ ou em $m$. Então agora precisamos calcular a razão dos perímetros né.

A2: Daí precisamos só calcular na proporção da área com o perímetro?

A3: Eu acho que sim, vamos tentar.

O comentário "a razão encontrada quando divide o valor de dois lados proporcionais em 
dois polígonos semelhantes e do perímetro é a mesma" do aluno A2 é um interpretante imediato que passa a se construir um objeto e indicar um novo signo. Com este novo signo tem-se um novo ciclo de interpretantes, conforme denotado na fala do aluno A3 "Então agora precisamos calcular a razão dos perímetros né". Esse comentário possui característica de interpretante dinâmico, por causar um efeito ao intérprete quando evidencia uma estratégia para busca da solução. Estratégia esta que seguidamente é aceita pelo grupo.

Quando 0 aluno A2 comenta "Daí precisamos só calcular na proporção da área com 0 perímetro?" tem-se um interpretante final, por parte dos alunos. Contudo, passa a ser um novo interpretante imediato quando produz um efeito no intérprete de calcular a razão entre os perímetros. O cálculo dos perímetros é um interpretante dinâmico por corresponder a uma interpretação do signo no intérprete. Estes interpretantes associados aos cálculos feitos pelos alunos provocam a produção do signo interpretante final representado no Quadro 3.

Quadro 3: Cálculo da área do lago, realizado pelos alunos

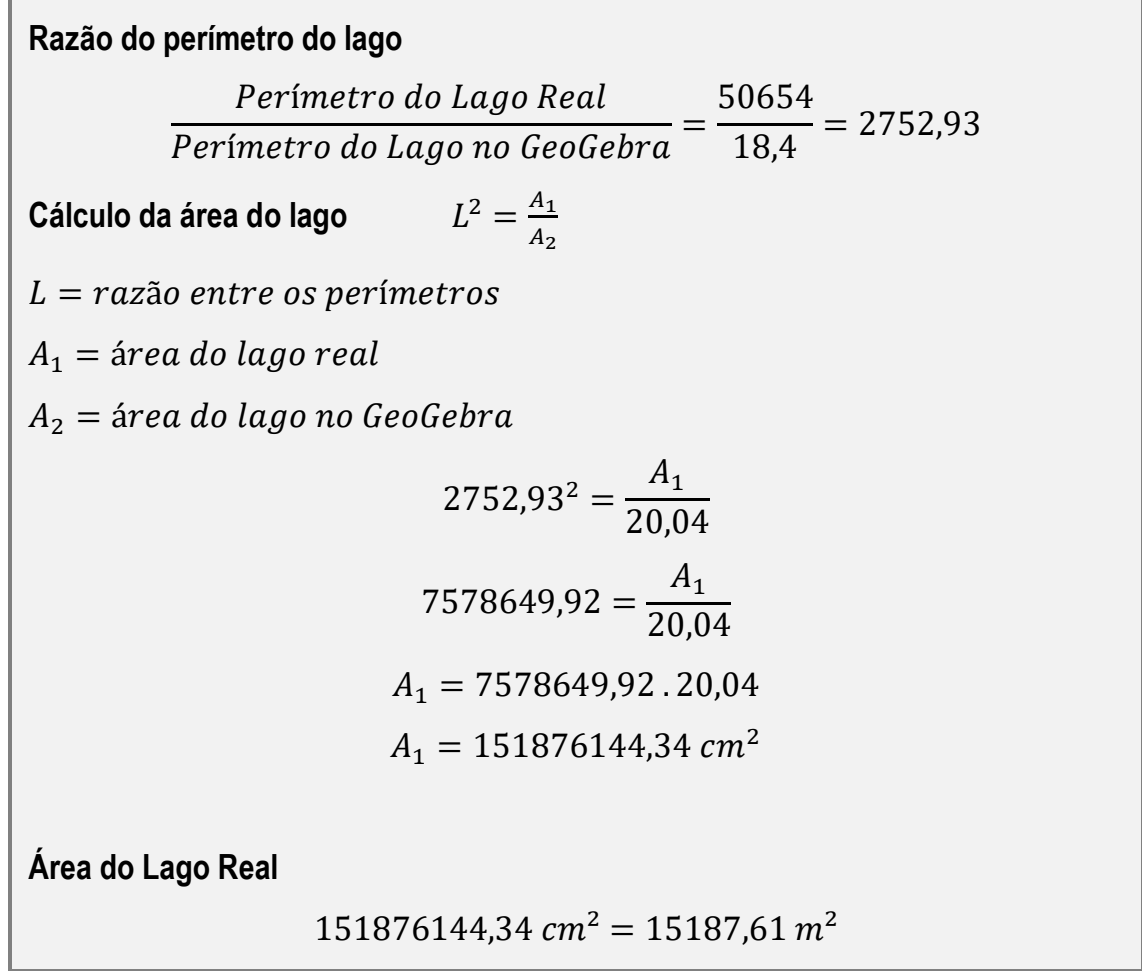

Fonte: Dados da Pesquisa

Esses cálculos, realizados para obter uma solução para a primeira etapa do problema em estudo, além de corresponder à uma solução elaborada pelo grupo, está em associação com a geração de interpretantes ao longo de todo o desenvolvimento da atividade de modelagem matemática. A resposta obtida pelo grupo de alunos caracteriza-se um interpretante final quando 
eles a assumem como satisfatória para o problema em estudo. Com isso, esse interpretante cessa, em um primeiro momento, o processo de semiose, processo de geração de interpretantes, nessa atividade de modelagem matemática, por eles assumirem que tal atividade foi finalizada.

Contudo, quando da socialização da atividade de modelagem matemática para todos os alunos da turma são questionados sobre o número de pedalinhos que cabem no lago e, nesse instante, percebem não terem respondido ao problema inicialmente proposto por eles. Sendo assim, retomam as informações relativas ao pedalinho - comprimento: 2,20 m. O Episódio 6 ilustra as discussões do grupo referente às próximas ações a serem assumidas.

\section{Episódio 6}

Prof.: Então o que vocês vão fazer com essas informações?

A3: Prof, primeiro a gente precisa saber quanto espaço esse pedalinho ocupa. [...]

A1: Professora, eu estava pensando, temos que calcular a área do pedalinho né?

Prof.: Isso, mas para isso vocês precisam identificar algumas coisas.

A3: Sim professora, o formato do pedalinho.

A2: Professora, eu acho que não é só o formato do peladinho, se ele gira, a gente precisa calcular todo o espaço para ele girar.

A1: Mas então a gente pode utilizar a imagem da parte de baixo do pedalinho que encontramos no site.

O comentário "Prof, primeiro a gente precisa saber quanto espaço esse pedalinho ocupa" do aluno A3 gera um novo ciclo de interpretantes. Essa afirmação é um interpretante imediato por sinalizar uma primeira impressão do aluno, mas também é um interpretante dinâmico porque revela um efeito que o interpretante imediato provoca ao intérprete. A fala de A1 "Professora, eu estava pensando, temos que calcular a área do pedalinho né?" denota tal efeito.

O interpretante dinâmico "a gente precisa calcular todo o espaço para ele girar" do aluno A2 denota um efeito no intérprete e carrega uma intenção que fica explicitada no interpretante final produzido por A1 ao comentar "Mas então a gente pode utilizar a imagem da parte de baixo do pedalinho que encontramos no site". Esse interpretante passa a constituir um objeto e indicar um 
novo signo que, associado à imagem do pedalinho inserida no GeoGebra, gera um novo ciclo de interpretantes. O Episódio 7 ilustra as discussões empreendidas pelo grupo nessa fase do desenvolvimento da atividade de modelagem matemática.

\section{Episódio 7}

Prof.: Porque vocês estão colocando a imagem do pedalinho no GeoGebra?

A2: Ah, prof, porque a base do pedalinho é um retângulo, e como a gente precisa fazer a circunferência por fora dela é mais fácil no GeoGebra.

$[\cdots]$

A1: Professora, a gente precisa calcula a área dessa circunferência né? Então, a gente vai utilizar a fórmula da área da circunferência. Mas para calcular o raio a gente vai ter que calcular a distância entre o centro da circunferência e a circunferência, só que isso eu não sei.

A3: Prof, os pontos do GeoGebra. A gente fez assim, inserimos a imagem no GeoGebra, daí colocamos os pontos nos extremos do pedalinho e traçamos um retângulo que é a base, daí as diagonais desse retângulo. Porque metade dessa diagonal é o raio da circunferência em que ele está inserido. É isso né?

Prof.: É sim.

A1: Então se é isso a gente precisa das coordenadas dos pontos do centro da circunferência e de um dos vértices do retângulo da base do peladinho.

O comentário "Ah, prof, porque a base do pedalinho é um retângulo, e como a gente precisa fazer a circunferência por fora dela é mais fácil no GeoGebra" do aluno A2, é um interpretante imediato porque expressa uma qualidade de impressão do signo sobre o intérprete. Da mesma forma, a fala do aluno A1 "Professora, a gente precisa calcular a área dessa circunferência né?" e a do aluno A2 "a gente vai utiliza a fórmula da área da circunferência" também tem conotação de interpretante imediato.

O interpretante dinâmico expresso na afirmação "Mas para calcular o raio a gente vai ter 
que calcular a distância entre o centro da circunferência e a circunferência, só que isso eu não sei" denota um efeito produzido pelo signo no intérprete e corresponde uma interpretação do signo por explicitar a indicação da utilização da fórmula da área da circunferência e necessidade do valor do raio.

Quando o aluno A3 fala: "A gente fez assim, inserimos a imagem no GeoGebra, daí colocamos os pontos nos extremos do pedalinho e traçamos um retângulo que é a base, daí as diagonais desse retângulo" revela um efeito que o signo causou no intérprete. Esse interpretante dinâmico gera outro interpretante dinâmico expresso na afirmação "Porque metade dessa diagonal é o raio da circunferência em que ele está inserido". Essas declarações associadas à Figura 3, que também é um interpretante dinâmico, provocam os alunos a pensarem em estratégias para obterem resposta ao problema em questão.

O cálculo da área da circunferência (Quadro 4), por apresentar uma intepretação do signo no intérprete, é um interpretante dinâmico que leva à produção de um interpretante final, já que eles assumem esse valor da área como uma resposta razoável em relação ao modo como tratam o espaço ocupado pelo pedalinho no lago.

Quadro 4: Cálculo da área do peladinho, realizado pelos alunos

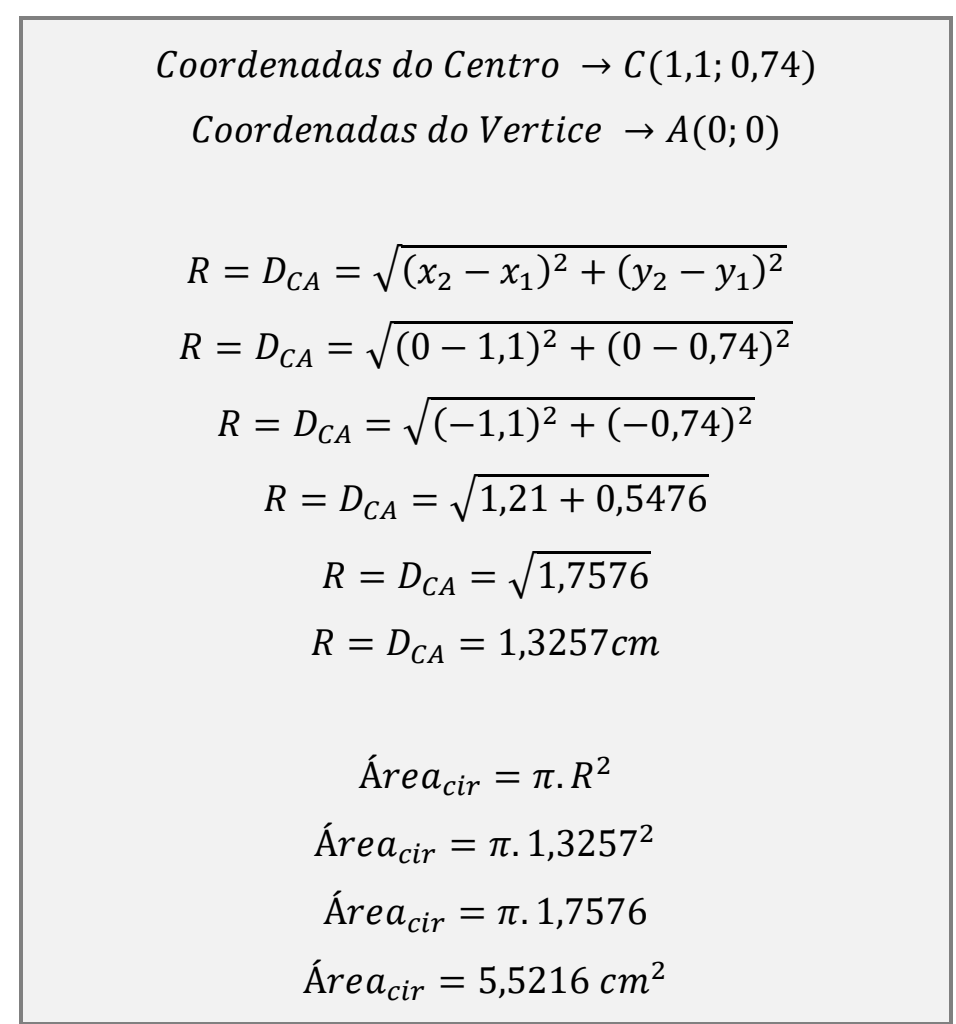

Fonte: Dados da Pesquisa 
Essa resposta obtida pelo grupo de alunos também assume conotação de interpretante dinâmico ao provocar neles um novo efeito. Tal efeito aparece ilustrado no Episódio 8.

\section{Episódio 8}

A3: Professora se a gente calculou a área da circunferência utilizando cada centímetro do GeoGebra como um metro do pedalinho real. Então essa área que a gente encontrou é em metros mesmo né.

Prof.: Sim.

A1: Então a área que cada pedalinho ocupa do lado é de 5,52 $\mathrm{m}^{2}$.

A2: Então é só a gente dividir a área do lago pela área do peladinho para saber quantos pedalinhos cabem no lago.

O comentário do aluno A3 "a gente calculou a área da circunferência utilizando cada centímetro do GeoGebra como um metro do pedalinho real" é um interpretante dinâmico por denotar uma intenção que o signo casou no intérprete, que se confirma na fala do aluno A1: "Então a área que cada pedalinho ocupa do lado é de 5,52 m²". Essa afirmação, interpretante imediato, se constitui um novo signo, que gera no intérprete um efeito expresso no interpretante dinâmico: "Então é só a gente dividir a área do lago pela área do peladinho para saber quantos pedalinhos cabem no lago". Esses interpretantes, associados ao Quadro 5, levam os alunos a produzirem um interpretante final para a situação em estudo.

Quadro 5: Cálculo da razão entre as áreas do pedalinho e do lago, realizado pelos alunos

$$
\frac{\text { Áre } a_{\text {lago }}}{\text { Áre } a_{\text {pedalinho }}}=\frac{15187,61 m^{2}}{5,5216 m^{2}}=2750,58 \text { pedalinhos }
$$

Fonte: Dados da Pesquisa

Esse cálculo, além de ser um interpretante dinâmico por revelar uma interpretação dos alunos sobre o problema em foco, se comporta como um interpretante final por ser assumido como uma resposta válida para tal problema. Assim, esse interpretante cessa o processo de semiose, processo de geração de signos, dessa atividade de modelagem matemática, já os alunos consideram ter obtido uma resposta para o problema por eles enunciado. 


\section{Algumas conclusões}

A análise da atividade de modelagem matemática que tem como problema "Quantos pedalinhos cabem no lago?", desenvolvida por alunos de uma primeira série do Ensino Médio, a partir de um tema por eles proposto, realizada a partir do objetivo enunciado neste estudo, denota que os alunos tiveram atitudes autônomas na busca por solução para o problema supracitado e que foi por eles formulado, como é esperado segundo os aportes teóricos de Modelagem Matemática. Além disso, o fato de os alunos, ao longo do desenvolvimento dessa atividade de modelagem matemática, se mostrar interessados e motivados a avançar na investigação do problema e obter uma solução para ele trouxe à tona uma variedade de signos que foram por eles produzidos.

Em todo o trânsito da situação inicial para a situação final há evidências — nos Episódios - de que os alunos dialogaram acerca de conhecimentos matemáticos e não matemáticos, manifestando suas impressões, pensamentos e conhecimentos por meio de signos. Esses signos foram produzidos, algumas vezes, em correspondência com o uso do GeoGebra, mas, também foram produzidos signos com base nas reações imediatas dos alunos, nos conhecimentos que eles mobilizaram e nas reflexões por eles realizadas. Nessas reflexões os alunos mostraram também colocar à prova seus conhecimentos - matemáticos e da situação em foco - quando os relacionavam, quando possível, com os conhecimentos que submergiam a partir da interação deles com o software GeoGebra. Sendo assim, esses signos, que representam ações e estratégias tomadas pelos alunos ao longo da atividade de modelagem matemática, têm conotações distintas (imediato, dinâmico e final) dependendo do que significam e evocam nos (ou para os) intérpretes (alunos).

Também é conveniente destacar que as intervenções do professor e o incentivo, seja em relação ao uso do GeoGebra ou a partir da dinâmica possibilitada nas aulas, favoreceu aos alunos a experiência de aprender Matemática, por meio da Modelagem Matemática, em um ambiente contextualizado tecnologicamente. Isso nos ajuda a pensar que práticas com essa característica podem contribuir para a aprendizagem dos alunos e também para o ensino da Matemática.

O estudo aqui relatado também proporciona inferir que ao longo do desenvolvimento dessa atividade de modelagem matemática os alunos tiveram oportunidade de construir e mobilizar conceitos diversos, para além de conceitos matemáticos, que foram expressos nas classes de interpretantes - imediato, dinâmico e final — que levaram à obtenção e aceite de uma 
resposta para o problema em estudo.

Foi a motivação dos alunos e a recorrência deles ao software GeoGebra, para elucidar ou compreender aspectos da situação que por vezes desconheciam ou precisavam saber para dar continuidade na investigação do problema em estudo, que favoreceu a produção de signos interpretantes e, portanto, o desenvolvimento da atividade de modelagem matemática. Nesse sentido, esse software teve um papel importante nessa atividade, principalmente em relação à visualização das imagens - do lago e do pedalinho -, à compreensão de aspectos que levaram ao levantamento das hipóteses. Foram os interpretantes produzidos em associação com 0 GeoGebra que possibilitaram a formulação de estratégias para resolver o problema em questão. Além disso, o processo de geração de interpretantes foi agilizado devido ao software. Nesse sentido, ponderamos que olhar para a produção dos alunos ao longo do desenvolvimento dessa atividade de modelagem matemática a partir de lentes da Semiótica favorece uma visão mais ampla a respeito dos conhecimentos que foram construídos por eles ou por eles mobilizados enquanto a desenvolviam. Isso pode sinalizar indicativos interessantes para o professor no que concerne à aprendizagem dos alunos em relação aos conceitos evidenciados ou emergentes na atividade como um todo.

Todos esses signos interpretantes, independente da conotação que tem, expressam reações imediatas, sugerem encaminhamentos ou favorecem reflexões que culminam na resolução da atividade de modelagem matemática e fazem emergir o processo de geração de signos denotado por Peirce (2005) por semiose.

Por fim, ressaltamos que o fato dos alunos terem se envolvido com Modelagem Matemática possibilitou o desenvolvimento de atitudes autônomas e os fez assumir papel central no seu processo de aprendizagem; ações essas tão discutidas e recorrentes nos debates que consideram uma educação matemática viva nas práticas de sala de aula.

\section{Referências}

ALMEIDA, Lourdes Maria Werle. Um olhar semiótico sobre modelos e modelagem: metáforas como foco de análise. Zetetiké, Campinas, v. 18, p. 387- 414, 2010.

ALMEIDA, Lourdes Maria Werle; DIAS, Michele Regiane. Um estudo sobre o uso da Modelagem Matemática como estratégia de ensino e aprendizagem. Bolema, Rio Claro, v. 17, n. 22, p. 19-36, jul./dez. 2004. 
ALMEIDA, Lourdes Maria Werle; SILVA, Karina Alessadra Pêssoa; VERONEZ, Michele Regiane Dias. Sobre a geração e a interpretação de signos em atividades de modelagem matemática. In: VI SEMINÁRIO INTERNACIONAL DE PESQUISA EM EDUCAÇÃO MATEMÁTICA, 2015, Pirenópolis. Anais do VI SIPEM. Pirenópolis: SBEM, 2015, p. 1-13.

ALMEIDA, Lourdes Maria Werle; SILVA, Karina Alessandra Pessôa. (Org.). Modelagem Matemática em foco. Rio de Janeiro: Ciência Moderna, 2014.

ALMEIDA, Lourdes Maria Werle; SILVA, Karina Pessôa; VERTUAN, Rodolfo Eduardo. Modelagem Matemática na Educação Básica. São Paulo: Contexto, 2013.

BORSSOI, Adriana Helena; SILVA, Karina Pêssoa; ALMEIDA, Lourdes Maria Werle. Atividades de Modelagem Matemática e uso da Tecnolocia: uma análise semiótica. In: VIII CONFERÊNCIA NACIONAL SOBRE MODELAGEM NA EDUCAÇÃO MATEMÁTICA, 2013, Santa Maria. Anais da VIII CNMEM: Modelagem Matemática: pesquisas, práticas e implicações para a Educação Matemática. Santa Maria: UFN, UFRGS, 2013, p. 1-15.

DENZIN, Norman K.; LINCOLN, Yvonna S. Introdução: a disciplina e a prática da pesquisa qualitativa. In: DENZIN, Norman e LINCOLN, Yonna (Orgs.). O planejamento da pesquisa qualitativa: teorias e abordagens. Tradução de Sandra Regina Netz. 2. ed. Porto Alegre: Artmed, 2006, p. 15-41.

FERREIRA, Emerson Pessoa. Semiótica visual na Educação Tecnológica: significações da imagem e discurso visual. 2006. 147f. Dissertação (Mestrado em Educação Científica e Tecnológica) - Centro de Ciências da Educação. Universidade Federal de Santa Catarina. Florianópolis.

GOLDENBERG, Mirian. A arte de pesquisa: como fazer pesquisa qualitativa em Ciências Sociais. Rio de Janeiro: Record, 1999.

GREEFRATH, Gilbert. Using Techenologies: New possibilities of Teacheing and Learning Modelling - Overview. In: KAISER, Gabriele; BLUM, Werner; FERRI, Rita Borromeo; STILLMAN, Gloria. (Ed.). Trends in Teaching and Learning of Mathematical Modelling: International Perspectives on the Teaching and Learnings of Mathematical Modellings. New York: Springer, 2011, p. 301-314.

HERTLEIF, Corinna. Dynamic Geometry software in Mathematical Modelling: about the role of programme-related self-efficacy ant attitudes towaresd learning with the software. In: 13th INTERNATIONAL CONFERENCE ON TECHNOLOGY IN MATHEMATICS TEACHING, 2017, Lyon. Proceedings of the ICTM13. Lyon: Ecole Normale Supérieure de Lyon, 2017, p. 124-133.

NÖTH, Winfried. Panorama da Semiótica: de Platão a Peirce. 4. ed. São Paulo: Annblume, 2008.

PEIRCE, Charles Sanders. Semiótica. Tradução de José Teixeira Coelho Neto. 3. ed. 2. reimp. São Paulo: Perspectiva, 2005.

SANTAELLA, Lucia. Matrizes da linguagem e pensamento: sonora, visual, verbal. 3. ed. São Paulo. lluminuras, 2009. 
SILLER, Hans Stefan; GREEFRATH, Gilbert. Mathematical modelling in class regarding to technology. In: DURAND-GUERRIR, Viviane; SOURY-LAVERGNE, Sophie; ARZARELLO, Ferdinando. (Ed). Procedings of the Sixth Congresso of the European Society for Research in Mathematics Education. Lyon: IRNP, 2010, p. 2136-2145.

SILVA, Karina Alessandra Pessôa. Modelagem Matemática e Semiótica: algumas relações. 2008. 262f. Dissertação (Mestrado em Ensino de Ciências e Educação Matemática) - Centro de Ciências Exatas. Universidade Estadual de Londrina. Londrina.

VERONEZ, Michele Regiane Dias; ALMEIDA, Lourdes Maria Werle. Sobre o papel dos signos em atividades de Modelagem Matemática. REnCiMa, São Paulo, v. 8, n. 3, p. 142-157. 2017.

VERTUAN, Rodolfo Eduardo. Um olhar sobre a Modelagem Matemática à luz da Teoria dos Registros de Representações Semiótica. 2007. 142f. Dissertação (Mestrado em Ensino de Ciências e Educação Matemática) - Centro de Ciências Exatas. Universidade Estadual de Londrina. Londrina. 